\title{
Appraisal of Techniques, Investigation and Analysis of Vitamin (B7) Biotin
}

\author{
Safila Naveed1, Fatima Qamar1, Syeda Sarah Abbas',2, Syed Hameez Jawed², Wajiha Raza1, \\ Mahera Khan', Bushra Iqbal ${ }^{1}$ \\ ${ }^{1}$ Faculty of Pharmacy, Jinnah University for Women, Karachi, Pakistan \\ ${ }^{2}$ Department of Pharmaceutics, Faculty of Pharmacy, University of Karachi, Karachi, Pakistan \\ Email: safila117@yahoo.com, syedasarahabbas@yahoo.com
}

Received 22 August 2015; accepted 9 September 2015; published 16 September 2015

Copyright (C) 2015 by authors and OALib.

This work is licensed under the Creative Commons Attribution International License (CC BY). http://creativecommons.org/licenses/by/4.0/

(c) (i) Open Access

\begin{abstract}
Biotin is also called vitamin B7, vitamin $\mathrm{B} 8$ or vitamin $\mathrm{H}$. Biotin is a water soluble compound and is colorless in appearance. Overall eight different types of biotin exist but only Biotin-D occurs naturally with its complete vitamin activity. It is mainly synthesized by mold, algae, bacteria, yeast and some plant species. There are different methods used to find the vitamins in nutrients and samples. This article is composed of the comprehensive review of the competitive techniques and various methods for the assay of biotin. High-pressure liquid chromatographic (HPLC), microbiological analysis and HPLC producer are adopted for the determination of biotin. An optimal analytical condition of biotin determination was performed by the HPCL method. The statistical parameters of the HPLC methods were compared and reviewed with other determination.
\end{abstract}

\section{Keywords}

Biotin, Biotin-D, HPLC Method, Vitamin B8, Vitamin H, Biological Method, Microbiological Analysis Subject Areas: Pharmacology

\section{Introduction}

Biotin, which is an essential vitamin, helps in the health of skin, nerve and digestive system, and assists in releasing energy and metabolism of fats, protein and carbohydrates [1]-[4]. It also helps in the formation of embryonic development [5]-[7]. It has wide function and effects on systemic processes and development [8] [9] assistance in immunity [10]. Biotin acts as prosthetic group of carboxylases; it is a hydro-soluble vitamin. Biotin also regulates gene expression unrelated to its role as carboxylase prosthetic group [11] [12]. Deficiency in the biotin may lead to the neurological disease and affect the skin and hair growths [13].

The glucose and carbohydrates are metabolized with the help of biotin [e]. Dakshinamurti et al. reported the 
evidence of the glucose metabolism and effects of biotin in the biotin deficient rats. The research carried out the Glucose Tolerance Test (GTT) curve in the biotin-deficient rats and significant results showed that the GTT curve is higher in the biotin-deficient rats than in the non-deficient rats [14]. The results indicate the reduction in the activity of hepatic glucokinase in the liver. It is responsible in glucose uptake in the liver. The effect of biotin on glucokinase is also observed in cultured rat hepatocytes and appears to be mediated through biotin-induced increases of cyclic GMP [14]. Later Chauhan et al. demonstrated the stimulatory effect of the biotin occurring at the level of transcription. This study helps to determine the role of biotin in the gene expression. The natural sources of biotin are fish, milk, egg yolks, liver and beans. Vitamin B7 (biotin) is also found in rice, wheat, nuts yeast, potatoes and cauliflower [15].

Maeda Y. et al. carried the research based on biotin deficiency in rats. The research concluded that biotin deficiency changes the activity and gene expression of urea cycle enzymes. For this experiment, Maeda Y. et al. used rats which were sub-divided into two groups: biotin-deficient rats (BD rats) and biotin-supplemented rats (BS rats) (Figure 1). The plasma ammonia concentration was found significantly higher in the BD rats than in the BS rats. These results define that the deficiency in biotin may lower the activity of ornithine transcarbamylase in lever [16].

\section{Methods of Analysis of Biotin B7}

\subsection{Liquid Chromatography (LC)}

(LC) is a separation technique used for the determination of the amino acids, protein and vitamins, in which the mobile phase is a liquid. It can be carried out in column or a plane. Now a day's liquid chromatography generally consumes very small particles packing's and a relatively high pressure is referred to as high pressure liquid chromatography (HPLC) [17].

\subsection{HPLC Operating Method}

\subsubsection{High Pressure Liquid Chromatography (HPLC) in Biotin}

In HPLC the sample is highly forced by a mobile phase liquid at high pressure through a column that is packed with a stationary phase composed of irregularly or porous spherically shaped particles, a porous monolithic layer, or a porous membrane. HPLC is divided into two different sub-classes based on the polarity of the mobile and stationary phases [17].

\subsubsection{Assay Procedure}

D. Scott Wilbur et al. carried out research to assess the relative binding of biotin derivatives with avidin and strept avidin for evaluation of biotin-Dye conjugates for use in an HPLC Assay. In this study HPLC is used to assess the relative association rats and dissociation rats of biotin derivative form avidin. In this experiment biotin dye conjugates were evaluated to determine their peak characteristics on two different size exclusion HPLC columns. Biotin-dye conjugates bound with avidin in the presence of equal quantity of biotin provided association rate relative to biotin has been studied. The percentage of biotin-Dye conjugates had tested $3 \times$ times slower than biotin The biotin-cyanocobalamin was selected as best assay for HPLC. The biotin sarcosine-cyanocobalamin conjucate is more rapid dissociation rate than other biotin-Dye conjugates; this was conformed in this research via HPLC assay [18].

Patil Ashih et al. carried out a simple, sensitive and fast method using HPLC for the determination of Biotin, for the experiment UV-visible water2489 detector is attached with HPLC. The chromatic separation was achieved with a mobile phase containing water. The output calibration curve was linear with correlation coefficient of 0.99. The methods has shown consistence recovery of biotin and made this method specific, accurate and precise [19].

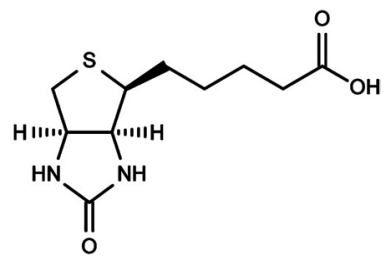

Figure 1. Structure of biotin. 
Brain Kanagy worked on the quantitation of biotin. It compare the Quant*Tag*Biotin kit with the traditional avidin binding spectrophotometric 2-(4'-hydroxyazobenzene) benzoic acid (HABA) assay procedure. The protocol was followed to determine the biotin as given with the kit. The solution was prepared and incubated for 30 minutes. A mass spectroscopy of the unlabeled protein and biotinylated protein has been performed. The result concluded the single spike is determined for the unlabeled protein and multiple spikes for the biotinylated protein. The result showed the enzymatic digestion may reduce in the commercial biotin quantitation kits [20].

Biotin is repeatedly linked with protein and nucleic acid covalently. Robert $\mathrm{H}$ Batchelor et al. worked on the protein binding biotin based on the micro plate based high throughput fluorometric assay. The assay uses the Alexa fluor 488 dye tagged avidin with the quencher dye HABA. The experiment shows the HABA quenches with the fluorescence resonance energy transfer (FERT). The result shows that fluorescence intensity is directly proportional to the amount of biotin in the sample. The direct relation between the fluoresce emission and biotin help to determine the accurate amount of the biotin present in the sample [21].

Pranee Nandhasri et al. worked on HPLC in early 80's to determine the biotin in foods using HPLC. Pranee Nandhasri found the royal jelly (RJ) and bee larvae are rich in biotin and HPLC is quit reliable, sensitive and satisfactory analytical method for the determination of the biotin [22]. Later on it is found Biotin also found in natural product like fish, milk, and egg yolk [15]. HPLC is now widely used analytic method for the determination of the biotin from natural products [23].

1) Advantage of chromatographic techniques

One of the advantages of chromatographic and electrophoretic techniques is that they allocate the analyst the freedom to doggedness a complex mixture by diverse routes utilizing different partition mechanisms supported on the chemical physical and physical possessions of the solute mixture [24].

\section{2) Disadvantage of HPLC and protein-binding assays}

The disadvantages of these assays are their lack of bigotry between biotin and its metabolites combining protein binding assay and HPLC can both be able to resolve this predicament [25].

\section{3) Microbiological assay procedure}

Essential nutrients are found in plants and animals, these essential nutrients are important for the human beings. Bishnoi Kapil et al. studied the antibiotic and vitamins using various strains of microbes via micro biological array. The experiment shows the microbiological array methods is better than chemical methods. The experiment is based upon the compression of growth bacteria by measuring the vitamin concentration and known concentration. The known concentrations are the standard concentration of vitamin with known activity. The procedure is accurate, precise but it requires time to determine the concentration of the bacterial growth [26].

\section{Result}

The result is based on the work carried out by the different researchers and their experiments. The previous studies have shown that the microbiological assay and high performance liquid chromatography are widely used in the detection of the vitamins, amino acids and other nutrients. This review article demonstrates the comparison between the microbiological assay and HPLC assay to evaluate the biotin in food, human body and animals. The previous study has revealed that HPLC is the most reliable, detailed and précised results that provide consistence result. Among all these advantages over microbiological assay to determine the biotin, the HPLC is the quit fast and time saving method [27].

\section{Discussion}

Various methods and procedures of vitamin determination were carried out by microbiological assay and high pressure liquid chromatography method both analytical methods were widely used from extensive period of time. The enzymatic activity of the long term incubation may reduce the accuracy of the result. This appraise has shown microbiological assay procedure of the biotin analysis and determination is renounce time consuming and less precise [21]. Preparation of the sample is difficult to handle for such long period of time. While research work has shown that HPLC is the classical method for the biotin analysis in food and samples. Pharmaceutical and food industries have vast use of the fortitude of vitamins in their products. Time is one of the important features in every diligence to balance the demand and supply, HPLC is preferred over microbiological assay to reduce the time of determination of results. Previous studies have also shown that the HPLC is sensitive, accurate, reliable and analytical tool for the research and industries. Our research group has also done these types of reviews on different 
topics [28]-[30].

\section{Conclusion}

Various methods and procedures for determination of vitamins and nutrients are used. Biotin is a specific vitamin helping in the metabolism of carbohydrates and protein. There are most widespread processes including microbiological assay and high pressure liquid chromatography technique. HPLC is nowadays the most competitive technique and classical method for biotin determination.

\section{References}

[1] Wang, J., Liu, X.D. and Schnute, W. (2000) Simultaneous Analysis of Water-Soluble Vitamins in Vitamin-Enriched Beverages and Multivitamin Dietary Supplements. UHPLC-MS/MS, Sunnyvale, CA.

[2] De Leenheer, A.P. and Lambert, W., Eds. (2000) Modern Chromatographic Analysis of Vitamins: Revised and Expanded. Vol. 84. CRC Press, Boca Raton.

[3] Marquet, A., Bui, B.T. and Florentin, D. (2001) Biosynthesis of Biotin and Lipoic Acid. Vitamins \& Hormones, 61, 51-101. http://dx.doi.org/10.1016/S0083-6729(01)61002-1

[4] Bellows, L. and Moore, R. (2012) Water-Soluble Vitamins: B-Complex and Vitamin C. Fact Sheet No. 9.312.

[5] Swartz, M.E. (2005) UPLC ${ }^{\mathrm{TM}}$ : An Introduction and Review. Journal of Liquid Chromatography \& Related Technologies, 28, 1253-1263. http://dx.doi.org/10.1081/JLC-200053046

[6] Watanabe, T., et al. (2009) Effects of Biotin Deficiency on Embryonic Development in Mice. Nutrition, 5, 78-84. http://dx.doi.org/10.1016/j.nut.2008.06.031

[7] Watanabe, T. and Endo, A. (1990) Teratogenic Effects of Maternal Biotin Deficiency on Mouse Embryos Examined at Midgestation. Teratology, 42, 295-300. http://dx.doi.org/10.1002/tera.1420420313

[8] Watanabe, T. (1996) Morphological and Biochemical Effects of Excessive Amounts of Biotin on Embryonic Development in Mice. Experientia, 52, 149-154. http://dx.doi.org/10.1007/BF01923361

[9] Báez-Saldaña, A., Díaz, G., Espinoza, B. and Ortega, E. (1998) Biotin Deficiency Induces Changes in Subpopulations of Spleen Lymphocytes in Mice. American Journal of Clinical Nutrition, 64, 431-437.

[10] Báez-Saldaña, A. and Ortega, E. (2004) Biotin Deficiency Accelerates Thymus Involution, Blocks Thymocyte Maturation and Decreases Nose-Rump Length in Mice. Journal of Nutrition, 134, 1979-1987.

[11] Rodriguez-Melendez, R. and Zempleni, J. (2003) Regulation of Gene Expression by Biotin. The Journal of Nutritional Biochemistry, 14, 680-690. http://dx.doi.org/10.1016/j.jnutbio.2003.07.001

[12] Dakshinamurti, K. and Chauhan, J. (1994) Biotin-Binding Proteins. In: Dakshinamurti, K., Ed., Vitamin Receptors: Vitamins as Ligands in Cell Communication, Vol. 1, Cambridge University Press, Cambridge, 200-249. http://dx.doi.org/10.1017/CBO9780511525391.010

[13] Thapar, R. and Venkatnarayan, K. (2013) A Case of Biotinidase Deficiency Presenting as Quadriparesis. Indian Journal of Clinical Practice, 24, 680-683.

[14] Dakshimamurti, K., Modi, V.V. and Mistry, S.P. (1968) Some Aspects of Carbohydrates Metabolism in Biotin-Deficient Rats. Experimental Biology and Medicine, 127, 396-400. http://dx.doi.org/10.3181/00379727-127-32699

[15] Dakshinamurti, K. and Cheah-Tan, C. (1968) Biotin-Mediated Synthesis of Hepatic Glucokinase in the Rat. Archives of Biochemistry and Biophysics, 127, 17-21. http://dx.doi.org/10.1016/0003-9861(68)90195-1

[16] Maeda, Y., Kawata, S., Inui, Y., Fukuda, K., Igura, T. and Matsuzawa, Y. (1996) Biotin Deficiency Decreases Ornithine Transcarbamylase Activity and mRNA in Rat Liver. Journal of Nutrition, 126, 61-66.

[17] Gruber, B.M., Anuszewska, E.L. and Skierski, J.S. (2001) Activation of Programmed Cell Death (Apoptosis) by Adriamycin in Human Neoplastic Cells. Mutation Research/Fundamental and Molecular Mechanisms of Mutagenesis, 484, 87-93. http://dx.doi.org/10.1016/S0027-5107(01)00256-1

[18] Wilbur, D.S., Pathare, P.M., Hamlin, D.K., Frownfelter, M.B., Kegley, B.B., Leung, W.-Y. and Gee, K.R. (2000) Evaluation of Biotin-Dye Conjugates for Use in an HPLC Assay to Assess Relative Binding of Biotin Derivatives with Avidin and Streptavidin. Bioconjugate Chemistry, 11, 584-598. http://dx.doi.org/10.1021/bc0000031

[19] Ashish, P., Radhika, R. and Shantaram, N. (2014) Analytical Method Development and Validation of Biotin in a Solid Dosage form by RP-HPLC. International Journal of Universal Pharmacy and Bio Sciences, 3, 525-535.

[20] Kanagy, B. (2013) An Accurate and Simple Spectrophotometric Assay System for Quantitation of Biotin: The Quant*Tag ${ }^{\mathrm{TM}}$ Biotin Kit. Vector Laboratories, Inc., Burlingame.

[21] Batchelor, R.H., Sarkez, A., Cox, W.G. and Johnson, I. (2007) Fluorometric Assay for Quantitation of Biotin Cova- 
lently Attached to Proteins and Nucleic Acids. BioTechniques, 43, 503-507. http://dx.doi.org/10.2144/000112564

[22] Nabas, Z.M.O.Y., Haddadin, M.S.Y. and Nazer, I.K. (2014) The Influence of Royal Jelly Addition on the Growth and Production of Short Chain Fatty Acids of Two Different Bacterial Species Isolated from Infants in Jordan. Pakistan Journal of Nutrition, 13, 43-49. http://dx.doi.org/10.3923/pjn.2014.43.49

[23] Lawrance, P. and Patel, I. (2014) The Determination of Biotin in Food Using HPLC. Government Chemist Program Report, National Measurement Office.

[24] Issaq, H.J., Conrads, T.P., Janini, G.M. and Veenstra, T.D. (2002) Methods for Fractionation, Separation and Profiling of Proteins and Peptides. Electrophoresis, 23, 3048-3061. http://dx.doi.org/10.1002/1522-2683(200209)23:17<3048::AID-ELPS3048>3.0.CO;2-L

[25] Hurst, W.J., Ed. (2002) Methods of Analysis for Functional Foods and Nutraceuticals. 2nd Edition, CRC Press, Boca Raton. http://dx.doi.org/10.1201/9781420014679

[26] Kapil, B., Mahesh, K., Vipin, S. and Deepika, G. (2012) Microbiological Assay for Vitamin B. International Research Journal of Pharmacy, 3, 74-82.

[27] Baur, B., Suormala, T., Bernoulli, C. and Baumgartner, E.R. (1998) Biotin Determination by Three Different Methods: Specificity and Application to Urine and Plasma Ultrafiltrates of Patients with and without Disorders in Biotin Metabolism. International Journal for Vitamin and Nutrition Research, 68, 300-308.

[28] Naveed, S., Farooq, S., Abbas, S.S., Jawed, S.H., Qamar, F., Hussain, M.Y. and Ali, I. (2015) Contemporary Trends in Novel Ophthalmic Drug Delivery System: An Overview. Open Access Library Journal, 2, e1497. http://dx.doi.org/10.4236/oalib.1101497

[29] Abbas, S.S., Naveed, S., Qamar, F., Zainab, S., Jawed, S.H., Kiran, S., Zehra, S. and Ali, Z.B. (2015) Autism Spectrum Disorder (ASD); A Threat To Social Communication. World Journal of Pharmaceutical and Life Sciences, 1, $203-205$.

[30] Naveed, S., Abbas, S.S., Qamar, F., Ali, Z.B., Kiran, S. and Zehra, S. (2015) Textaphrenia; Turmoil for Adults. World Journal of Pharmaceutical and Life Sciences, 1, 70-72. 